\title{
REAVI
}

\section{COMPORTAMENTO DOS UNIVERSITÁRIOS DE INSTITUIÇÃO PÚBLICA E PRIVADA EM RELAÇÃO AO USO DAS REDES SOCIAIS: UM ESTUDO COMPARATIVO}

\section{BEHAVIOR OF UNIVERSITY STUDENTS FROM PUBLIC AND PRIVATE INSTITUTIONS IN RELATION TO THE USE OF SOCIAL NETWORKS: A COMPARATIVE STUDY}

\author{
Claudio Luiz Chiusoli* \\ Alex Ferreira Leite Padilha** \\ Ariani Aparecida Rodrigues ${ }^{* * *}$ \\ Ariéli Aparecida Rodrigues \\ Alex Junior Santos
}

\begin{abstract}
RESUMO
Atualmente, as redes sociais são um meio de se expressar; poucas pessoas as tinham, contudo isso mudou e, hoje em dia, elas se tornaram uma exigência, sendo utilizadas até mesmo pelas empresas e se tornando um diferencial competitivo. O objetivo do estudo é analisar como as redes sociais influenciam o comportamento e atitude de compra dos universitários de uma instituição pública e outra privada. Foi realizado por meio de uma pesquisa bibliográfica, sendo classificada, quanto à metodologia utilizada, como um estudo quantitativo, mediante amostragem não probabilística e por cotas em duas instituições de ensino superior, uma pública e outra particular, com 100 universitários. Os principais achados indicam que 70\% dos acadêmicos concordam que as redes sociais facilitam o contato com o produto; da mesma forma, $70 \%$ consideram importante que as empresas tenham redes sociais. Por outro lado, $49 \%$ concordam que as redes sociais influenciam na hora da compra e para $47 \%$ as lojas oferecem facilidades de vendas por meio delas. Muito embora, a segurança oferecida pelas redes sociais tenha apenas $29 \%$ de aprovação e $15 \%$ somente acreditem que a qualidade do produto é a mesma que a descrita nas redes sociais. Por fim, entre as redes sociais mais utilizadas para compra aparecem o Whatsapp (48\%), o Facebook (34\%) e o Instagram (14\%). Como contribuição, foi possível entender o comportamento dos acadêmicos, que se trata de um público jovem e mais conectado, o que pode ajudar as organizações a criarem estratégias específicas de acordo com a característica desse grupo.
\end{abstract}

Palavras-chave: Redes sociais. Comportamento do consumidor. Compras online.

\begin{abstract}
Nowadays social networks are a way of expressing themselves; few people have had them, however that ended up changing, and nowadays they have become a requirement, being used even by companies and becoming a competitive differential. The objective of the study is to analyze how social networks influence the behavior and buying attitude of university students from a public and a private institution. It was carried out by means of a bibliographic research and, regarding the methodology used, it is considered a quantitative study, by means of nonprobabilistic sampling and by quotas in two higher education institutions, one public and the

\footnotetext{
* UNICENTRO - UNIVERSIDADE DO CENTRO OESTE/PR E-mail: prof.claudio.unicentro@ gmail.com ** UNICENTRO - UNIVERSIDADE DO CENTRO OESTE/PR E-mail: alexpadilha435@outlook.com *** UNICENTRO - UNIVERSIDADE DO CENTRO OESTE/PR E-mail: arianirodrigues01@ gmail.com **** UNICENTRO - UNIVERSIDADE DO CENTRO OESTE/PR E-mail: rodriguesarieli2016@gmail.com ***** UNICENTRO - UNIVERSIDADE DO CENTRO OESTE/PR E-mail: alexjuniorviana88@ gmail.com
} 
other private, with 100 university students. The main findings indicate that $70 \%$ of academics agree that social networks facilitate contact with the product; likewise, $70 \%$ consider it important that companies have social networks. On the other hand, $49 \%$ agree that social networks influence the time of purchase; and for $47 \%$ the stores offer sales facilities through them. Although, for $29 \%$ of academics, the security offered by social networks has only $29 \%$ approval, and only $15 \%$ believe that the quality of the product is the same as described on social networks. Finally, among the most used social networks for purchase are Whatsapp (48\%), followed by Facebook (34\%) and, lastly, Instagram (14\%). As a contribution, it was possible to understand the behavior of academics, which is a young and more connected audience, what can help organizations create specific strategies according to the characteristics of this group.

Keywords: Social networks. Consumer behavior. Online shopping.

Data de submissão: 26 de novembro de 2019.

Data de aprovação: 10 de maio de 2020.

Disponibilidade: http://www.revistas.udesc.br/index.php/reavi/index

\section{INTRODUÇÃO}

O mercado está cada vez mais competitivo, portanto quem está envolvido nesse meio precisa acompanhar as novas tendências. E com o crescimento do uso das redes sociais são formas de um modo de expressão, que antes, poucas pessoas as utilizavam, contudo isso mudou e, hoje em dia, elas são uma exigência. Por meio do uso das redes sociais, como meio de comunicação, obteve-se um relacionamento mais próximo com os clientes.

Os consumidores estão inseridos em uma sociedade por meio das relações sociais que desenvolvem durante sua existência, começando primeiro pelo ambiente familiar, em seguida no ambiente escolar, na local que residem e convivem, e, por final, no seu ambiente de trabalho, surgindo assim uma sociedade ligada por redes sociais (TOMAÉL; ALCARÁ; CHIARA, 2005).

Nas redes sociais, as pessoas tem sua própria atividade e características culturais, considerando sua afinidade com outros indivíduos, que representam a rede. Com a rede social, os clientes têm uma visão transparente da empresa, de uma forma positiva, e possuem um contato direto; os clientes sabem o que estão fazendo, o que pensam e o que querem, mas é preciso conquistá-los com as publicações, porque no feed de notícias dos nossos clientes potenciais, também aparecem as publicações, anúncios e imagens dos concorrentes (ARCE et al., 2018).

As redes sociais de maiores destaques são o Facebook, Twitter e Instagram, só o Facebook tem mais de 80 milhões usuários no Brasil, e cerca de $75 \%$ das empresas o utilizam, por o considerarem importante na aproximação com seus clientes, bem como para conquistar novos seguidores, interagindo e tendo um contato mais direto ao facilitar a divulgação e venda de produtos e serviços (BRITO; NASCIMENTO; LOPES, 2018; THE STATISTICS PORTAL, 2020).

Com isso, o foco é manter e estreitar os relacionamentos com os clientes, conquistandoos por meio de anúncios e da coerência do seu produto; e a velocidade de como ocorre a troca de informações que as redes sociais proporcionam faz com que aumente o relacionamento entre cliente e empresa. Porém, ainda há pessoas que não utilizam as redes sociais, por isso é preciso saber que não é simplesmente criar uma página empresarial e sair postando imagens de produtos, é preciso ter uma estratégia, ter planejamento e conhecer o seu público-alvo (OKADA; SOUZA, 2011). 
É preciso estar sempre aberto a novas experiências, acompanhar a concorrência, buscar um maior contato nas redes. O meio virtual evolui de uma forma muito rápida, então é necessário acompanhar essa evolução, e para que tudo dê certo, as organizações devem ter planejamento e estratégias, para que assim desenvolvam a melhor forma para manter seu crescimento e contato com seu grupo de clientes (MARTELETO, 2001).

Diante do exposto, o estudo em questão torna-se relevante, pois se entende que investigar temas relativos a quanto a rede social influencia o consumo e facilita o contato com o produto, bem como se é importante que a empresa atue nas redes sociais, e se a ideia de qualidade do produto descrita nas redes sociais pode ajudar a melhor entender a expectativa desse grupo de consumidor.

Assim, o estudo se justifica, tendo em vista que entender o comportamento dos acadêmicos torna-se importante e interessante, uma vez que essa geração de usuários está conectada e, a partir desse meio, as redes sociais permitem a construção de um melhor processo de comunicação, sem a necessidade de contato físico ou interação ao vivo (MOREIRA, 2017).

Considerando o exposto, o problema de pesquisa tem por finalidade investigar: há diferenças de comportamento de consumo entre os universitários de uma instituição pública e de uma instituição privada quanto ao uso das redes sociais, e como estas interferem na sua atitude e finalidade de uso?

O objetivo do estudo é analisar como as redes sociais influenciam o comportamento e atitude de compra dos universitários de uma instituição pública e outra privada.

E como objetivo específico, buscou-se identificar: i) se as redes sociais influenciam na hora de realizar a compra; ii) se facilitam o contato com o produto; iii) se dão segurança em adquirir o produto; e iv) o uso das principais redes sociais.

Dessa forma, o artigo está estruturado em cinco seções, considerando a introdução, e após o referencial teórico: evolução das redes sociais, comportamento do consumidor e marketing digital. Na sequência, a terceira seção detalha a metodologia utilizada, a qual foi exploratória e quantitativa. Na quarta seção, os resultados do estudo são discutidos à luz da literatura abordada. Na última seção, a conclusão, sintetizando os principais achados, a contribuição da pesquisa, bem como sua limitação, e, por fim, sugestões para futuras pesquisas da área.

\section{REFERENCIAL TEÓRICO}

Essa pesquisa apresenta uma revisão bibliográfica sobre o comportamento e atitude do usuário das redes sociais, abordando mais especificamente a evolução das redes sociais, o comportamento do consumidor e o marketing digital.

\subsection{EVOLUÇÕES DAS REDES SOCIAIS}

As interligações digitais criaram uma nova leitura na dinâmica após a era analógica e se transformaram em conexões no espaço web, de acordo com Recuero (2011). Os impactos das redes sociais são evidentes e atuais, a partir do momento que os usuários começaram a utilizar as mídias sociais como Facebook, Linkedin, Youtube, Twitter e outros para promover relacionamento e agregando mais pessoas (SOARES; MONTEIRO; PLINIO, 2015).

A partir da evolução do uso das redes sociais, o Brasil tem-se destacado no cenário mundial, onde conforme a revista americana Forbes, de 2013, o país de maior população da América do Sul, tem aproximadamente $79 \%$ dos usuários da internet com taxas aproximando as taxas de uso dos EUA (GOMES; REIS, 2016). 
E ainda, o Brasil é o $5^{\circ}$ país do mundo em número de usuários na internet, aproximadamente $37 \%$ utilizam as redes sociais e ficam conectados em torno de 10 horas por mês (BRITO; NASCIMENTO; LOPES, 2018).

A partir da aparição das redes sociais houve alteração quanto a forma de comunicação entre as pessoas e empresas, e Hutter et al. (2013) argumentam que essa tecnologia proporcionou que as mídias sociais mudem a forma de comunicação e impactado de forma significativa a comunicação de marketing como ferramenta. Segundo Araújo e Rios (2010), a internet já está inserido no dia a dia do consumidor, mesmo que alguns ainda não tenham pleno conhecimentos sobre a internet.

E Gobé (2012), expõe que o consumidor entendem que as compras são planejadas e as vezes compulsivas e que os produtos de consumo são parte do seu dia a dia. Essa forma de comprar, leva a um novo formato de relacionamento de mercado e diante da internet, não se pode mais desconhecer que a rede está em plena ascensão quanto ao uso.

\subsection{COMPORTAMENTOS DO CONSUMIDOR}

De acordo com Giglio (2010), o comportamento de compra não está no comprador em si, mas sim fora dela, tem a ver como são as regras dos grupos que ela está inserida ou ao aquele que gostaria de fazer parte. Blackwell, Miniard e Engel (2013) acrescentam que o comportamento de do consumidor é pensado no motivo da compra, sob a premissa de que é mais fácil criar estratégias para influenciar os compradores após entender o porquê tomam certas decisões de consumo de algum produto ou marca.

Como sugere Moreno e Lopes (2018), o envolvimento baseado nas interações cria um relacionamento de fidelidade do comprador em relação a uma determinada marca, uma forma de gerar lealdade, transformando os clientes em promotores da empresa.

Segundo Giglio (2010), o estudo do comportamento do consumidor tem raízes do campo da economia, uma vez que, o consumo é orientado por decisões inteligentes a respeito da aceitação de um produto ou serviço e quais os recursos necessários para adquiri-los. Deste modo, entender o comportamento do consumidor é conhecer quais os processos envolvidos na seleção dos indivíduos ou dos grupos envolvidos, de forma a saber como compram, como utilizam e como é realizado seu descarte, tudo isso, com a proposta da satisfação de seus desejos e necessidades (SOLOMON, 2011).

O conceito de marketing enfatiza que o marketing rentável começa com a descoberta e o entendimento das necessidades do consumidor, para depois desenvolver um mix de marketing que satisfaça a essas necessidades (PETER; DONNELLY, 2013).

Assim, o entendimento dos consumidores, suas necessidades e o comportamento de compra são partes integrantes do marketing bem-sucedido, pois a partir das mídias de massa como a impressa, o rádio e televisão, foi o foco das empresas para uma maior divulgação dos produtos e serviços (JENKINS, 2014).

Com o mercado mais competitivo é necessário estudar e acompanhar o comportamento do consumidor, a ponto de resolver possíveis falhas e encontrar oportunidades, agindo antes dos concorrentes (SILVA RABELO; MESQUITA, 2018).

$\mathrm{Na}$ abordagem de Kotler e Armstrong (2015) o comportamento do consumidor refere-se aos consumidores finais que adquirem bens e serviços para consumo pessoal ou familiar.

Essa atitude envolve a forma de como escolhem, usam e compram os serviços e produtos, na intenção de sanar seus desejos e necessidades, para posterior descarte (RIBEIRO, 2015).

E normalmente, os próprios compradores não sabem precisamente o que influencia seu comportamento de compra, podendo ser um ato involuntário (KOTLER; ARMSTRONG, 2015). 
Para Cobra (2011), o comportamento de compra do cliente é muitas vezes influenciado pelo perfil sócio econômico, bem como pelas características culturais, sociais, pessoais e psicológicas, fazendo com que os gestores de marketing tentem compreender seu atitude e hábito.

De modo particular aspectos culturais, sociais, pessoais e psicológicas são fatores decisivos para compreender seus desejos e preferências de comportamento de compra de um consumidor (KOTLER; ARMSTRONG, 2015).

\subsection{MARKETING DIGITAL}

O crescimento exponencial do marketing digital é um caminho sem volta; mais de $90 \%$ dos processos de compras têm início nas plataformas de busca online (PEÇANHA, 2014).

As empresas têm utilizado cada vez mais o marketing digital em suas ações estratégicas e isso é possível em função da tecnologia e do acesso à internet, que permitiu o desenvolvimento de novas formas de comunicação entre as empresas e os consumidores (FERREIRA; FERREIRA, 2018).

Para Okada e Souza (2011), a utilização do marketing digital como parte de uma ação estratégica torna-se uma elo de ligação entre os clientes e as empresas, melhorando e muito o processo de entre as partes.

Para Limeira (2010) o marketing digital é um conjunto de ações de marketing por meio dos canais digitais mediante o uso da internet que tem sido amplamente utilizado pelas empresas. Assim, tornou-se um propósito das organizações utilizar para realização de seus negócios, focado nas diversas mídias sociais, como Facebook, Instagram, Linkedin, Youtube, entre outras, de forma a estreitar um contato mais perto com os consumidores, com a proposta de entender melhor sua necessidade e desejo, facilitando uma maior aproximação e criando diferenciais competitivos.

Ainda de acordo com Kotler e Keller (2010), o marketing envolve a descoberta das necessidades dos consumidores do ponto de vista cultural, social, pessoal e psicológica, de forma que, por meio das plataformas de ferramentas digitais, ao suprir suas necessidades tenha como proposta final das empresas, tornarem-se mais lucrativas.

\section{PROCEDIMENTOS METODOLÓGICOS}

Este estudo foi realizado por meio de uma revisão bibliográfica, que, de acordo com Gil (2017), é elaborada baseadas em temas publicados em livros, artigos científicos e outras publicações.

Quanto à natureza das variáveis e o objetivo, o método utilizado foi quantitativo, que significa quantificar opiniões, dados, na forma de coleta de informações, assim também como um emprego e cursos, e técnicas como porcentagem média e mediana (AAKER; KUMAR; DAY, 2001).

Quanto à população e unidade de observação, foram um grupo de universitários de duas instituições, uma pública e outra de iniciativa privada, e participaram do estudo os acadêmicos que declaravam fazer uso das redes sociais.

Quanto às variáveis investigadas, foram 12 no total, sendo 3 perfis (gênero, faixa etária e instituição pública e privada), e essas questões abordavam sobre: influência da rede social; facilidade do contato com o produto; se as lojas oferecem facilidade por meio das redes sociais; se é importante que a empresa tenha redes sociais; se quando a empresa vende por redes sociais 
oferece segurança; se a qualidade do produto é a mesma descrita nas redes sociais; se quando compra pela rede social utiliza Whatsapp, Facebook ou Instagram.

Quanto às escalas utilizadas, predominou a ordinal, mediante escala de 3 pontos concordo/indiferente/discordo; sendo que a escala ordinal é obtida pela classificação dos objetivos ordenados em função de alguma variável em comum (AAKER; KUMAR; DAY, 2001).

Quanto à técnica de amostragem, foi utilizada a não probabilística por conveniência e por cotas quanto à instituição, sendo que 50 entrevistas foram conduzidas para cada uma das instituições, pública e privada, em um total de 100 universitários. Gil (2017) classifica como amostragem não probabilística aquela que não apresenta fundações matemáticas ou probabilísticas, dependendo unicamente de critérios do pesquisador.

Quanto à forma da coleta dos dados e abordagem, trabalhou-se por meio de levantamento mediante entrevistas pessoais entre universitários de uma instituição pública e outra particular com sede na mesma cidade pesquisada. Para Aaker, Kumar e Day (2001), a entrevista pessoal é geralmente escolhida quando se precisa coletar uma grande quantidade de informações e as questões são complexas ou envolvem tarefas, como ordinais, ou avaliar estímulos visuais como figuras e anúncios.

Quanto à procedência dos dados, foram utilizados dados primários, pois são informações coletadas para o propósito da questão (KOTLER; ARMSTRONG, 2015).

Quanto ao recorte, é feito um recorte transversal, que tratou-se de uma pesquisa feita em um momento em específico e uma única vez (FLICK, 2012).

Quanto à técnica estatística, a análise dos dados consistiu em análises univariadas e bivariadas, com base em frequências absolutas e relativas. As medidas de associação foram testadas por meio do teste não paramétrico, o Qui-Quadrado (SIEGEL; CASTELLAN, 2017), considerando o nível de significância abaixo de 5\% (p-valor < 0,05). No caso, se isso ocorrer, acarretará que devem ser rejeitadas as hipóteses propostas, quando forem apontadas diferenças significativas ao nível de significância adotada. Assim, entende-se que as proporções dos resultados entre as variáveis independentes foram distintas.

Assim, têm-se as três hipóteses da pesquisa, que foram:

H0: Não há diferença significativa na opinião dos universitários em relação às variáveis pesquisadas segmentadas por gênero.

H1: Não há diferença significativa na opinião dos universitários em relação às variáveis pesquisadas segmentadas por faixa etária.

H2: Não há diferença significativa na opinião dos universitários em relação às variáveis pesquisadas segmentadas por instituição pública e privada.

\section{RESULTADOS E DISCUSSÃO}

Essa seção é composta de 14 Quadros, sendo que dos Quadros 1 a 3 apresenta-se o perfil dos universitários quanto ao gênero, faixa etária e instituição em que estuda (privada ou pública). A seguir, os Quadros 4 a 12 apontam os resultados das variáveis estudadas segmentadas por gênero, faixa etária e instituição que estuda. O Quadro 13 exibe o resultado geral do estudo; e, por fim, o Quadro 14 resume os resultados do teste estatístico, Qui-Quadrado, provando o grau de significância para cada variável, apontando se deve ou não rejeitar as hipóteses H0, H1 e H2. 


\section{REAVI}

Quadro 1 - Gênero

\begin{tabular}{|l|c|c|c|c|c|}
\hline \multicolumn{1}{|c|}{ Gênero } & \multicolumn{2}{c|}{ Faixa etária } & \multicolumn{2}{c|}{ Instituição ensino } & Total \\
\hline Até 19 & $\mathbf{2 0 +}$ & Privada & Pública & \\
\hline Feminino & $51,5 \%$ & $47,1 \%$ & $50,0 \%$ & $50,0 \%$ & $50,0 \%$ \\
\hline Masculino & $48,5 \%$ & $52,9 \%$ & $50,0 \%$ & $50,0 \%$ & $50,0 \%$ \\
\hline Total & $100,0 \%$ & $100,0 \%$ & $100,0 \%$ & $100,0 \%$ & $100,0 \%$ \\
\hline
\end{tabular}

Fonte: Dados da pesquisa (2019).

O Quadro 1 mostra que 51,5\% dos respondentes do sexo feminino possuem a faixa etária até 19 anos; 52,9\% do público masculino possuem mais de 20 anos, sabendo que as instituições de ensino possuem $50 \%$ cada uma.

Quadro 2 - Faixa etária

\begin{tabular}{|l|c|c|c|c|c|}
\hline \multicolumn{1}{|c|}{ Faixa etária } & \multicolumn{2}{c|}{ Gênero } & \multicolumn{2}{c|}{ Instituição ensino } & Total \\
\hline & Feminino & Masculino & Privada & Pública & \\
\hline Até 19 & $68,0 \%$ & $64,0 \%$ & $68,0 \%$ & $64,0 \%$ & $66,0 \%$ \\
\hline $20+$ & $32,0 \%$ & $36,0 \%$ & $32,0 \%$ & $36,0 \%$ & $34,0 \%$ \\
\hline Total & $100,0 \%$ & $100,0 \%$ & $100,0 \%$ & $100,0 \%$ & $100,0 \%$ \\
\hline
\end{tabular}

Fonte: Dados da pesquisa (2019).

De acordo com o Quadro 2, 68\% do sexo feminino possui a faixa etária até 19 anos, $64 \%$ do público masculino possui mais de 20 anos, sabendo que as instituições de ensino possuem $50 \%$ cada uma. Verifica-se com este resultado que a maioria dos participantes da pesquisa possui a idade até 19 anos $(66 \%)$.

Quadro 3 - Instituição de ensino

\begin{tabular}{|l|c|c|c|c|c|}
\hline \multicolumn{1}{|c|}{ Instituição } & \multicolumn{2}{c|}{ Gênero } & \multicolumn{2}{c|}{ Faixa etária } & Total \\
\hline & Feminino & Masculino & Até 19 & $\mathbf{2 0 +}$ & \\
\hline Privada & $50,0 \%$ & $50,0 \%$ & $51,5 \%$ & $47,1 \%$ & $50,0 \%$ \\
\hline Pública & $50,0 \%$ & $50,0 \%$ & $48,5 \%$ & $52,9 \%$ & $50,0 \%$ \\
\hline Total & $100,0 \%$ & $100,0 \%$ & $100,0 \%$ & $100,0 \%$ & $100,0 \%$ \\
\hline
\end{tabular}

Fonte: Dados da pesquisa (2019).

De acordo com o Quadro 3, 50\% dos respondentes do sexo feminino e masculino frequentam instituição de ensino particular e pública, sabendo que a maioria possui a faixa etária até 19 anos.

Quadro 4 - As redes sociais influenciam na hora da compra

\begin{tabular}{|l|c|c|c|c|c|c|c|}
\hline \multicolumn{1}{|c|}{ Escala } & \multicolumn{2}{c|}{ Gênero } & \multicolumn{2}{c|}{ Faixa etária } & \multicolumn{2}{c|}{ Instituição ensino } & Total \\
\hline & Feminino & Masculino & Até 19 & $\mathbf{2 0 +}$ & Privada & Pública & \\
\hline Concordo & $50,0 \%$ & $48,0 \%$ & $51,5 \%$ & $44,1 \%$ & $46,0 \%$ & $52,0 \%$ & $49,0 \%$ \\
\hline Indiferente & $42,0 \%$ & $46,0 \%$ & $45,5 \%$ & $41,2 \%$ & $48,0 \%$ & $40,0 \%$ & $44,0 \%$ \\
\hline Discordo & $8,0 \%$ & $6,0 \%$ & $3,0 \%$ & $14,7 \%$ & $6,0 \%$ & $8,0 \%$ & $7,0 \%$ \\
\hline Total & $100,0 \%$ & $100,0 \%$ & $100,0 \%$ & $100,0 \%$ & $100,0 \%$ & $100,0 \%$ & $100,0 \%$ \\
\hline
\end{tabular}

Fonte: Dados da pesquisa (2019).

O Quadro 4 se refere à variável 'as redes sociais influenciam na hora da compra', e mostra um p-valor de 0,881 para a hipótese H0, um p-valor de 0,095 para a hipótese H1, e um pvalor de 0,708 para a hipótese $\mathrm{H} 2$, o que indica que as hipóteses não podem ser rejeitadas.

Tem-se que $50 \%$ do público feminino concorda que as redes sociais influenciam na hora da compra, $48 \%$ do público masculino concorda com essa informação, sabendo que 51,5\% têm até 19 anos, e $52 \%$ frequentam instituição de ensino pública. De fato, com o surgimento das

Revista Eletrônica do Alto Vale do Itajaí - REAVI, v.09, nº 14, p. 055-068, ago. 2020.

ISSN: 2316-4190, DOI 10.5965/2316419009142020055 
mídias sociais, a forma de comunicação entre consumidor e empresas tem impactado significativamente a comunicação de marketing, o que pode ser um influenciador no ato da compra (HUTTER et al., 2013).

Quadro 5 - As redes sociais facilitam o contato com o produto

\begin{tabular}{|l|c|c|c|c|c|c|c|}
\hline \multicolumn{1}{|c|}{ Escala } & \multicolumn{2}{c|}{ Gênero } & \multicolumn{2}{c|}{ Faixa etária } & \multicolumn{2}{c|}{ Instituição ensino } & Total \\
\hline & Feminino & Masculino & Até 19 & $\mathbf{2 0 +}$ & Privada & Pública & \\
\hline Concordo & $68,0 \%$ & $72,0 \%$ & $80,3 \%$ & $50,0 \%$ & $72,0 \%$ & $68,0 \%$ & $70,0 \%$ \\
\hline Indiferente & $22,0 \%$ & $16,0 \%$ & $12,1 \%$ & $32,4 \%$ & $16,0 \%$ & $22,0 \%$ & $19,0 \%$ \\
\hline Discordo & $10,0 \%$ & $12,0 \%$ & $7,6 \%$ & $17,6 \%$ & $12,0 \%$ & $10,0 \%$ & $11,0 \%$ \\
\hline Total & $100,0 \%$ & $100,0 \%$ & $100,0 \%$ & $100,0 \%$ & $100,0 \%$ & $100,0 \%$ & $100,0 \%$ \\
\hline
\end{tabular}

Fonte: Dados da pesquisa (2019).

O Quadro 5 se refere à variável 'as redes sociais facilitam o contato com o produto'; mostra um p-valor de 0,773 para a hipótese H0, um p-valor de 0,007 para a hipótese H1, e um pvalor de 0,733 para a hipótese $\mathrm{H} 2$.

Dessa forma, os resultados indicam que $72 \%$ do público masculino concorda que as redes sociais facilitam o contato com o produto, e ainda destaca-se que quem mais concorda com essa afirmação são os universitários que frequentam a instituição de ensino particular, com $72 \%$. Porém, mesmo diante desse indicadores, as hipóteses $\mathrm{H} 0$ e H2 não podem ser rejeitadas.

Por outro lado, há diferenças estatísticas entre os universitários quanto à faixa etária, uma vez que $80,3 \%$ dos que concordam têm até 19 anos, contra $50 \%$ daqueles com idade acima de 20 anos, o que se estabelece que a hipótese $\mathrm{H} 1$ deve ser rejeitada.

Corroborando os achados, a internet faz parte da cultura contemporânea, mesmo que uma parte da população não tenha conhecimentos tão profundos sobre ela, é por meio da rede social, entre várias atribuições, que se estabelece um maior contato com produtos para consumo (ARAÚJO; RIOS, 2010).

Quadro 6 - As lojas oferecem facilidade de vendas por meio das redes sociais

\begin{tabular}{|l|c|c|c|c|c|c|c|}
\hline \multicolumn{1}{|c|}{ Escala } & \multicolumn{2}{c|}{ Gênero } & \multicolumn{2}{c|}{ Faixa etária } & \multicolumn{2}{c|}{ Instituição ensino } & Total \\
\hline Concordo & Feminino & Masculino & Até 19 & $\mathbf{2 0 +}$ & Privada & Pública & \\
\hline Indiferente & $48,0 \%$ & $46,0 \%$ & $51,5 \%$ & $38,2 \%$ & $48,0 \%$ & $46,0 \%$ & $47,0 \%$ \\
\hline Discordo & $34,0 \%$ & $32,0 \%$ & $36,4 \%$ & $26,5 \%$ & $32,0 \%$ & $34,0 \%$ & $33,0 \%$ \\
\hline Total & $18,0 \%$ & $22,0 \%$ & $12,1 \%$ & $35,3 \%$ & $20,0 \%$ & $20,0 \%$ & $20,0 \%$ \\
\hline
\end{tabular}

Fonte: Dados da pesquisa (2019).

O Quadro 6 se refere à variável 'as lojas oferecem facilidade de vendas por meio das redes sociais'; mostra um p-valor de 0,882 para a hipótese $\mathrm{H} 0$, um p-valor de 0,023 para a hipótese H1, e um p-valor de 0,975 para a hipótese H2, o que indica que as hipóteses H0 e H2 não podem ser rejeitadas.

Por outro lado, a hipótese H1 deve ser rejeitada, uma vez que se aponta diferença significativa ao verificar que o grupo de universitários até 19 anos concorda com essa afirmação, com um índice de 51,5\%, contra 38,2\% dos que têm acima de 20 anos.

Considerando que ainda há pessoas que não utilizam as redes sociais, torna-se necessário que haja planejamento e organização das empresas, pois não é simplesmente criar uma página empresarial e sair postando imagens dos produtos, é importante conhecer bem a atitude e comportamento do público-alvo (OKADA; SOUZA, 2011). 
Quadro 7 - É importante que as empresas tenham redes sociais

\begin{tabular}{|l|c|c|c|c|c|c|c|}
\hline \multicolumn{1}{|c|}{ Escala } & \multicolumn{2}{c|}{ Gênero } & \multicolumn{2}{c|}{ Faixa etária } & \multicolumn{2}{c|}{ Instituição ensino } & Total \\
\hline Concordo & Feminino & Masculino & Até 19 & $\mathbf{2 0 +}$ & Privada & Pública & \\
\hline Indiferente & $76,0 \%$ & $64,0 \%$ & $75,8 \%$ & $58,8 \%$ & $76,0 \%$ & $64,0 \%$ & $70,0 \%$ \\
\hline Discordo & $22,0 \%$ & $30,0 \%$ & $21,2 \%$ & $35,3 \%$ & $20,0 \%$ & $32,0 \%$ & $26,0 \%$ \\
\hline Total & $2,0 \%$ & $6,0 \%$ & $3,0 \%$ & $5,9 \%$ & $4,0 \%$ & $4,0 \%$ & $4,0 \%$ \\
\hline
\end{tabular}

Fonte: Dados da pesquisa (2019).

O Quadro 7 se refere à variável 'é importante que as empresas tenham redes sociais'; apresenta um p-valor de 0,345 para a hipótese H0, um p-valor de 0,214 para a hipótese H1, e um p-valor de 0,387 para a hipótese $\mathrm{H} 2$, o que indica que as hipóteses não podem ser rejeitadas.

$\mathrm{E}$, confirmando os resultados, verifica-se que os grupos têm comportamentos parecidos, onde $76 \%$ do público feminino concorda que é importante que as empresas tenham redes sociais, sabendo que 75,8\% têm até 19 anos, e 76\% frequentam instituição de ensino particular.

Quadro 8 - A empresa que vende por meio das redes sociais oferece segurança no ato da compra

\begin{tabular}{|l|c|c|c|c|c|c|c|}
\hline \multicolumn{1}{|c|}{ Escala } & \multicolumn{2}{c|}{ Gênero } & \multicolumn{2}{c|}{ Faixa etária } & \multicolumn{2}{c|}{ Instituição ensino } & Total \\
\hline & Feminino & Masculino & Até 19 & $\mathbf{2 0 +}$ & Privada & Pública & \\
\hline Concordo & $32,0 \%$ & $26,0 \%$ & $28,8 \%$ & $29,4 \%$ & $36,0 \%$ & $22,0 \%$ & $29,0 \%$ \\
\hline Indiferente & $48,0 \%$ & $52,0 \%$ & $50,0 \%$ & $50,0 \%$ & $44,0 \%$ & $56,0 \%$ & $50,0 \%$ \\
\hline Discordo & $20,0 \%$ & $22,0 \%$ & $21,2 \%$ & $20,6 \%$ & $20,0 \%$ & $22,0 \%$ & $21,0 \%$ \\
\hline Total & $100,0 \%$ & $100,0 \%$ & $100,0 \%$ & $100,0 \%$ & $100,0 \%$ & $100,0 \%$ & $100,0 \%$ \\
\hline
\end{tabular}

Fonte: pesquisa 2019

O Quadro 8 se refere à variável 'a empresa que vende por meio das redes sociais oferece segurança no ato da compra'; indica um p-valor de 0,803 para a hipótese H0, um p-valor de 0,996 para a hipótese $\mathrm{H} 1$, e um p-valor de 0,293 para a hipótese $\mathrm{H} 2$, o que demonstra que as hipóteses não podem ser rejeitadas.

Cerca de $48 \%$ do público feminino acha indiferente que a empresa que vende por meio das redes sociais ofereça segurança no ato da compra, sabendo que 50\% têm de 19 a 20 anos, e $56 \%$ frequentam instituição de ensino pública. Isso sugere que o excesso de informações lançado diariamente à população, pelos mais variados espaços, desperta a dúvida sobre a veracidade de cada anúncio, conferindo juízo de valor às recomendações advindas de pessoas comuns (JENKINS, 2014).

Quadro 9 - A qualidade do produto é a mesma que a descrita nas redes sociais

\begin{tabular}{|l|c|c|c|c|c|c|c|}
\hline \multicolumn{1}{|c|}{ Escala } & \multicolumn{2}{c|}{ Gênero } & \multicolumn{2}{c|}{ Faixa etária } & \multicolumn{2}{c|}{ Instituição ensino } & Total \\
\hline & Feminino & Masculino & Até 19 & $\mathbf{2 0 +}$ & Privada & Pública & \\
\hline Concordo & $18,0 \%$ & $12,0 \%$ & $13,6 \%$ & $17,6 \%$ & $18,0 \%$ & $12,0 \%$ & $15,0 \%$ \\
\hline Indiferente & $56,0 \%$ & $66,0 \%$ & $63,6 \%$ & $55,9 \%$ & $58,0 \%$ & $64,0 \%$ & $61,0 \%$ \\
\hline Discordo & $26,0 \%$ & $22,0 \%$ & $22,7 \%$ & $26,5 \%$ & $24,0 \%$ & $24,0 \%$ & $24,0 \%$ \\
\hline Total & $100,0 \%$ & $100,0 \%$ & $100,0 \%$ & $100,0 \%$ & $100,0 \%$ & $100,0 \%$ & $100,0 \%$ \\
\hline
\end{tabular}

Fonte: Dados da pesquisa (2019).

O Quadro 9 se refere à variável 'a qualidade do produto é a mesma que a descrita nas redes sociais'; aponta um p-valor de 0,555 para a hipótese $\mathrm{H} 0$, um p-valor de 0,743 para a hipótese $\mathrm{H} 1$, e um p-valor de 0,688 para a hipótese $\mathrm{H} 2$, o que indica que as hipóteses não podem ser rejeitadas.

Desse modo, verifica-se que $66 \%$ do público masculino afirma ser indiferente que a qualidade do produto não seja a mesma que a descrita nas redes sociais, sabendo que 63,6\% têm 
até 19 anos, e 64\% frequentam a instituição de ensino pública. Destaca-se também que apenas $15 \%$ dos universitários concordam com a afirmação que a qualidade do produto é a mesma.

Conforme exposto por Gobé (2012), esse dado reforça a ideia de que as pessoas consideram os produtos como parte integrante de suas vidas, onde o consumidor pede uma nova modalidade de relações de mercado, por esse motivo a importância da rede social, no entanto, os indicadores ainda sugerem que persiste a sensação de que é necessário ver o produto pessoalmente.

Quadro 10 - Quando compro pela rede social costumo utilizar o Whatsapp

\begin{tabular}{|l|c|c|c|c|c|c|c|}
\hline \multicolumn{1}{|c|}{ Escala } & \multicolumn{2}{c|}{ Gênero } & \multicolumn{2}{c|}{ Faixa etária } & \multicolumn{2}{c|}{ Instituição ensino } & Total \\
\hline & Feminino & Masculino & Até 19 & $\mathbf{2 0 +}$ & Privada & Pública & \\
\hline Concordo & $50,0 \%$ & $46,0 \%$ & $53,0 \%$ & $38,2 \%$ & $46,0 \%$ & $50,0 \%$ & $48,0 \%$ \\
\hline Indiferente & $28,0 \%$ & $26,0 \%$ & $28,8 \%$ & $23,5 \%$ & $30,0 \%$ & $24,0 \%$ & $27,0 \%$ \\
\hline Discordo & $22,0 \%$ & $28,0 \%$ & $18,2 \%$ & $38,2 \%$ & $24,0 \%$ & $26,0 \%$ & $25,0 \%$ \\
\hline Total & $100,0 \%$ & $100,0 \%$ & $100,0 \%$ & $100,0 \%$ & $100,0 \%$ & $100,0 \%$ & $100,0 \%$ \\
\hline
\end{tabular}

Fonte: pesquisa 2019

O Quadro 10 se refere à variável 'quando compro pela rede social costumo utilizar o Whatsapp'; mostra um p-valor de 0,786 para a hipótese H0, um p-valor de 0,088 para a hipótese $\mathrm{H} 1$, e um p-valor de 0,796 para a hipótese $\mathrm{H} 2$, sugerindo que as hipóteses não podem ser rejeitadas. Entre os universitário do público feminino, $50 \%$ concordam que costumam utilizar o Whatsapp; quanto à faixa etária, o índice de concordância é de 53\% entre os com até 19 anos, e de $50 \%$ entre aqueles que estudam em instituição de ensino pública.

Quadro 11 - Quando compro pela rede social costumo utilizar o Facebook

\begin{tabular}{|l|c|c|c|c|c|c|c|}
\hline \multicolumn{1}{|c|}{ Escala } & \multicolumn{2}{c|}{ Gênero } & \multicolumn{2}{c|}{ Faixa etária } & \multicolumn{2}{c|}{ Instituição ensino } & Total \\
\hline & Feminino & Masculino & Até 19 & $\mathbf{2 0 +}$ & Privada & Pública & \\
\hline Concordo & $34,0 \%$ & $34,0 \%$ & $36,4 \%$ & $29,4 \%$ & $32,0 \%$ & $36,0 \%$ & $34,0 \%$ \\
\hline Indiferente & $22,0 \%$ & $28,0 \%$ & $28,8 \%$ & $17,6 \%$ & $24,0 \%$ & $26,0 \%$ & $25,0 \%$ \\
\hline Discordo & $44,0 \%$ & $38,0 \%$ & $34,8 \%$ & $52,9 \%$ & $44,0 \%$ & $38,0 \%$ & $41,0 \%$ \\
\hline Total & $100,0 \%$ & $100,0 \%$ & $100,0 \%$ & $100,0 \%$ & $100,0 \%$ & $100,0 \%$ & $100,0 \%$ \\
\hline
\end{tabular}

Fonte: pesquisa 2019

O Quadro 11 se refere à variável 'quando compro pela rede social costumo utilizar o Facebook'; mostra um p-valor de 0,748 para a hipótese H0, um p-valor de 0,199 para a hipótese H1, e um p-valor de 0,828 para a hipótese H2, o que indica que as hipóteses não podem ser rejeitadas. Os índices entre os estudantes por gênero são iguais, ambos com 34\%, tanto o público feminino quanto o masculino concordam que costumam utilizar o Facebook. Por outro lado, entre os mais jovens, com até 19 anos, o índice é de 36\%, e entre os que frequentam a instituição de ensino pública é de $36 \%$, contra $32 \%$ dos estudantes que estão na instituição particular.

Quadro 12 - Quando compro pela rede social costumo utilizar o Instagram

\begin{tabular}{|l|c|c|c|c|c|c|c|}
\hline \multicolumn{1}{|c|}{ Escala } & \multicolumn{2}{|c|}{ Gênero } & \multicolumn{2}{c|}{ Faixa etária } & \multicolumn{2}{c|}{ Instituição ensino } & Total \\
\hline Concordo & Feminino & Masculino & Até 19 & $\mathbf{2 0 +}$ & Privada & Pública & \\
\hline Indiferente & $18,0 \%$ & $10,0 \%$ & $18,2 \%$ & $5,9 \%$ & $14,0 \%$ & $14,0 \%$ & $14,0 \%$ \\
\hline Discordo & $26,0 \%$ & $28,0 \%$ & $25,8 \%$ & $29,4 \%$ & $28,0 \%$ & $26,0 \%$ & $27,0 \%$ \\
\hline Total & $56,0 \%$ & $62,0 \%$ & $56,1 \%$ & $64,7 \%$ & $58,0 \%$ & $60,0 \%$ & $59,0 \%$ \\
\hline
\end{tabular}

Fonte: Dados da pesquisa (2019).

O Quadro 12 se refere à variável 'quando compro pela rede social costumo utilizar o Instagram'; mostra um p-valor de 0,514 para a hipótese H0, um p-valor de 0,244 para a hipótese

Revista Eletrônica do Alto Vale do Itajaí - REAVI, v.09, nº 14, p. 055-068, ago. 2020.

ISSN: 2316-4190, DOI 10.5965/2316419009142020055 
H1, e um p-valor de 0,973 para a hipótese H2, o que indica que as hipóteses não podem ser rejeitadas. Cerca de $28 \%$ do público masculino afirma que é indiferente a utilizar o Instagram, e quanto à faixa etária o índice é de $29 \%$ entre aqueles com mais de 20 anos, e de $28 \%$ entre os estudantes de instituição de ensino particular.

Assim, considerando os achados nesse estudo, pode-se evidenciar que as redes sociais promovem interações entre seus usuários e novos negócios, confirmando que os maiores destaques são o Facebook, Twitter e Instagram, que permitem uma maior interação e contato mais direto ao facilitar a divulgação e venda de produtos e serviços (BRITO; NASCIMENTO; LOPES, 2018; THE STATISTICS PORTAL, 2020).

Quadro 13 - Resumo da pesquisa.

\begin{tabular}{|c|c|c|c|c|}
\hline Variáveis & Concordo & Indiferente & Discordo & Total \\
\hline Quadro 4 - As redes sociais influenciam na hora da compra & $49,0 \%$ & $44,0 \%$ & $7,0 \%$ & $100,0 \%$ \\
\hline $\begin{array}{l}\text { Quadro } 5 \text { - As redes sociais facilitam o contato com o } \\
\text { produto }\end{array}$ & $70,0 \%$ & $19,0 \%$ & $11,0 \%$ & $100,0 \%$ \\
\hline $\begin{array}{l}\text { Quadro } 6 \text { - As lojas oferecem facilidade de vendas por meio } \\
\text { das redes sociais }\end{array}$ & $47,0 \%$ & $33,0 \%$ & $20,0 \%$ & $100,0 \%$ \\
\hline $\begin{array}{l}\text { Quadro } 7 \text { - É importante que as empresas tenham redes } \\
\text { sociais }\end{array}$ & $70,0 \%$ & $26,0 \%$ & $4,0 \%$ & $100,0 \%$ \\
\hline $\begin{array}{c}\text { Quadro } 8 \text { - A empresa que vende por meio das redes sociais } \\
\text { oferece segurança }\end{array}$ & $29,0 \%$ & $50,0 \%$ & $21,0 \%$ & $100,0 \%$ \\
\hline $\begin{array}{l}\text { Quadro } 9 \text { - A qualidade do produto é a mesma que a descrita } \\
\text { nas redes sociais }\end{array}$ & $15,0 \%$ & $61,0 \%$ & $24,0 \%$ & $100,0 \%$ \\
\hline $\begin{array}{l}\text { Quadro } 10 \text { - Quando compro pela rede social costumo utilizar } \\
\text { o Whatsapp }\end{array}$ & $48,0 \%$ & $27,0 \%$ & $25,0 \%$ & $100,0 \%$ \\
\hline $\begin{array}{l}\text { Quadro } 11 \text { - Quando compro pela rede social costumo utilizar } \\
\text { o Facebook }\end{array}$ & $34,0 \%$ & $25,0 \%$ & $41,0 \%$ & $100,0 \%$ \\
\hline $\begin{array}{l}\text { Quadro } 12 \text { - Quando compro pela rede social costumo utilizar } \\
\text { o Instagram }\end{array}$ & $14,0 \%$ & $27,0 \%$ & $59,0 \%$ & $100,0 \%$ \\
\hline
\end{tabular}

Fonte: Autores (2019).

Em resumo, apresenta-se os resultados do estudo. Conforme o Quadro 13, as variáveis com maior índice de concordância, com $70 \%$, são para o 'quanto é importante que as empresas tenham rede social' e que 'as redes sociais facilitam o contato com o produto'.

Por outro lado, os menores índice de concordância foram para as variáveis que descrevem, `se a qualidade do produto é a mesma que a descrita nas redes sociais`, com 15\%, e 'Quando compro pela rede social costumo utilizar o Instagram', com $14 \%$.

Quadro 14 - Resumo do teste estatístico não paramétrico: Qui Quadrado

\begin{tabular}{|l|c|c|c|c|c|c|}
\hline Variáveis & P-Valor & $\begin{array}{c}\text { Teste de } \\
\text { hipótese - } \\
\text { Gênero }\end{array}$ & P- Valor & $\begin{array}{c}\text { Teste de } \\
\text { hipótese -Faixa } \\
\text { Etária }\end{array}$ & P- Valor & $\begin{array}{c}\text { Teste de hipótese } \\
\text { Instituição }\end{array}$ \\
\hline Quadro 4 & 0,881 & Não rejeitar H0 & 0,095 & Não rejeitar H1 & 0,708 & Não rejeitar H2 \\
\hline Quadro 5 & 0,733 & Não rejeitar H0 & $0,007 *$ & Rejeitar H1 & 0,733 & Não rejeitar H2 \\
\hline Quadro 6 & 0,882 & Não rejeitar H0 & $0,023 *$ & Rejeitar H1 & 0,975 & Não rejeitar H2 \\
\hline Quadro 7 & 0,345 & Não rejeitar H0 & 0,214 & Não rejeitar H1 & 0,387 & Não rejeitar H2 \\
\hline Quadro 8 & 0,803 & Não rejeitar H0 & 0,996 & Não rejeitar H1 & 0,293 & Não rejeitar H2 \\
\hline Quadro 9 & 0,555 & Não rejeitar H0 & 0,743 & Não rejeitar H1 & 0,688 & Não rejeitar H2 \\
\hline Quadro 10 & 0,786 & Não rejeitar H0 & 0,088 & Não rejeitar H1 & 0,796 & Não rejeitar H2 \\
\hline Quadro 11 & 0,748 & Não rejeitar H0 & 0,199 & Não rejeitar H1 & 0,828 & Não rejeitar H2 \\
\hline Quadro 12 & 0,514 & Não rejeitar H0 & 0,244 & Não rejeitar H1 & 0,973 & Não rejeitar H2 \\
\hline
\end{tabular}

Fonte: autores (2019) - significativo a $5 \%(\mathrm{p}<0,05)^{*}$ 
A partir da análise do Quadro 14, aponta-se os resultados do teste não paramétrico Qui Quadrado, o grau de significância para cada variável estudada, e se as hipóteses postuladas devem ou não ser rejeitadas.

\section{CONSIDERAÇÕES FINAIS}

Como considerações finais, entende-se que o objetivo do trabalho foi atingido, uma vez que procurou analisar como as redes sociais influenciam o comportamento e a atitude de compra dos universitários de uma instituição pública e outra privada. Por meio do teste Qui Quadrado foi possível verificar que as atitudes e comportamentos são semelhantes em relação às variáveis investigadas na pesquisa, por isso, a hipótese H0, H1 e H2 não podem ser rejeitadas.

Apenas para os acadêmicos quanto à idade houve opinião diferente do ponto de vista estatístico para a questão que abordava sobre o quanto 'as redes sociais facilitam o contato com o produto' e se 'as lojas oferecem facilidade de vendas por meio das redes sociais', ficando evidente que os universitários mais jovens, até 19 anos, são os que mais concordavam com essas questões, assim sendo, a hipótese $\mathrm{H} 2$ deve ser rejeitada.

Dessa forma, reitera-se os principais achados do estudo, que indicam que $70 \%$ dos acadêmicos concordam que as redes sociais facilitam o contato com o produto, da mesma forma, $70 \%$ consideram importante que as empresas tenham redes sociais. Por outro lado, $49 \%$ concordam que as redes sociais influenciam na hora da compra; e, para $47 \%$, as lojas oferecem facilidades de vendas por meio delas. Muito embora, para $29 \%$ dos acadêmicos a segurança oferecida pelas redes sociais tem apenas $29 \%$ de aprovação, e somente $15 \%$ acreditam que a qualidade do produto é a mesma que a descrita nas redes sociais. Por fim, entre as redes sociais mais utilizadas para a compra aparecem o Whatsapp (48\%), em seguida o Facebook (34\%) e, por último, o Instagram (14\%).

A contribuição da pesquisa foi identificar o perfil do consumidor universitário a partir de uso de diferentes redes sociais, apontando-se as mais utilizadas. Além disso, observou-se o comportamento desse público em relação a forma como entendem a influência das redes sociais no processo de compra, como se sentem a respeito da qualidade dos produtos e segurança oferecidas.

A limitação da pesquisa é que o estudo está restrito ao público universitário de uma instituição privada e uma instituição de ensino público em relação à análise. E, da mesma forma, como a amostra foi não probabilística, não é possível fazer inferências estatísticas, assim, a análise deve ficar restrita à população investigada.

A análise também serve como base para trabalhos futuros, a fim de identificar outras redes sociais que influenciam os acadêmicos, ou até mesmo aumentar a cobertura da pesquisa em outras regiões, abarcando mais instituições e faixas etárias distintas.

\section{REFERÊNCIAS}

ARCE, Yuri Fernando Simões et al. Modelo de Rede Social Virtual para Inclusão Digital e Social. Renote, [s.1.], v. 16, n. 1, p. 1-9, 21 ago. 2018.

AAKER, KUMAR, DAY, de Pesquisa Marketing. São Paulo: Atlas, 2001.

ARAÚJO, Gislene Freitas e RIOS, Riverson. Estratégias do Marketing Político Digital aplicadas à campanha presidencial de Barack Obama. Universidade Federal do Ceará, Fortaleza, 2010. 
BLACKWELL, R. D.; MINIARD, P. W.; ENGEL, J. F. Comportamento do consumidor. 9. Ed. São Paulo: Cengage Learning; 2013.

BRITO, Bianca Camila Xavier; NASCIMENTO, Ademir Macedo; LOPES, Charlie Silva. O Uso das Redes Sociais Virtuais no Relacionamento com o Cliente: um estudo sobre as empresas de moda em Recife. Gestão. Org, v. 16, n. 3, p. 258-263, 2018.

COBRA, Marcos. Administração de Marketing. São Paulo: Atlas, 2011.

FLICK, Uwe. Introdução à metodologia de pesquisa: um guia para iniciante. São Paulo: Penso Editora, 2012.

GIL, Antônio Carlos Como elaborar projetos de pesquisa. 6. ed. São Paulo: Atlas, 2017.

GIGLIO, E. M. O comportamento do Consumidor. 4. ed. São Paulo: Cengage Learning, 2010.

GOBÉ, Marc. Publicidade não é o final da comunicação, mas o início da conversa. 2012.

Disponível em: http://www.marketingdeconteudo.com.br/comportamento-do-consumidordigital/publicidadenao-e-o-final-da-comunicacao-mas-o-inicio-da-conversa/. Acesso em: 30 set. 2019.

GOMES, C, F.; REIS, H, M. Marketing Digital: sites x redes sociais no Brasil. Revista interface Tecnológica da Fatec. Taquaritinga. 2016.

HUTTER, K., HAUTZ, J., DENNHARDT, S., e FÜLLER, J. (2013). The impact of user interactions in social media on brand awareness and purchase intention: the case of MINI on Facebook. Journal of Product \& Brand Management, acessado dia 30 de setembro de 2019.

JENKINS, Henry. Cultura da Conexão: criando valor e significado por meio da mídia propagável. São Paulo: Aleph, 2014.

FERREIRA, João Batista; FERREIRA, Maicon Figueiredo. A Utilização do Marketing Digital em uma Empresa Prestadora de Serviços. Revista da Universidade Vale do Rio Verde, v. 16, n. 2, 2018.

KOTLER, Philip, ARMSTRONG, Gary, Princípios de Marketing. 15 ed. São Paulo: Pearson Education do Brasil, 2015.

KOTLER, Philip, KELLER, Kevin Lane. Administração de Marketing. 12a Edição. São Paulo: Prentice Hall, 2010.

LIMEIRA, Tania M. Vidigal. E-marketing. 2. ed. São Paulo: Saraiva, 2010.

MARTELETO, Regina Maria. Análise de redes sociais: aplicação nos estudos de transferência da informação. Ciência da Informação, Brasília, v. 30, n. 1, p. 71-81, jan./abr. 2001. 
MOREIRA, Rodrigo. Redes Sociais e seu Impacto no Comportamento Humano. 2017. Disponível em: https://www.profissionaisti.com.br/2017/06/redes-sociais-e-seu-impacto-nocomportamento-humano/. Acesso em: 27 ago. 2019.

MORENO, Diego Domingues; LOPES, Evandro Luiz. Programas de fidelidade: fronteiras atuais e futuras direções. Desafio Online, v. 6, n. 2, 2018.

OKADA, Sionara; Ioco, SOUZA, Eliane Moreira Sá de. Estratégias de marketing digital na era da busca. Revista Brasileira de Marketing, São Paulo, v. 10, n. 1, p 46-72, jan./abr. 2011. Disponível em:<www.spell.org.br/documentos/download/5413〉. Acesso em: 20 jul. 2019.

PEÇANHA, Vitor. Marketing Digital: O que é isso, afinal? Marketing de Conteúdo. Dezembro, 2014. Disponível em: Acesso em: 10 set. 2019.

PETER, P. J.; DONNELLY, J. H. JR. Introdução ao marketing: criando valor para os clientes. São Paulo: Saraiva 2013.

RECUERO, Raquel. Redes sociais na internet. Porto alegre: sulina, 2011.

RIBEIRO, Lucyara (org). Marketing social e comportamento do consumidor. São Paulo: Pearson Education Brasil, 2015.

SIEGEL, Sidney; CASTELLAN, Jr, N. John Estatística Não Paramétrica para as Ciências do Comportamento. Artmed-Bookman. São Paulo, 2017.

SILVA RABELO, Maria Helena; MESQUITA, Darlene Faria. Comportamento do consumidor: a influência da marca no processo decisório de compra em uma concessionária de veículos leves em uma cidade do centro-oeste de minas gerais. Revista Acadêmica Conecta FASF, v. 3, n. 1, 2018.

SOARES, R, F.; MONTEIRO, R.; PLINIO, R.; Marketing digital e marketing de relacionamento: interação e engajamento como determinantes do crescimento de páginas do Facebook. NAVUS - Revista de Gestão e Tecnologia, vol. 5, núm. 3, julho-setembro, 2015.

SOLOMON, Michael R. O comportamento do consumidor: comprando, possuindo e sendo. 9. Ed. Porto Alegre: Bookman, 2011.

THE STATISTICS PORTAL. Number of Facebook users in Brazil from 2014 to 2019 (in millions). Disponível em: <Disponível em: http://www.statista.com/statistics/244936/number-offacebook-users-in-brazil/ > . Acesso em: 2242020.

TOMAÉL, Maria Inês; ALCARÁ, Adriana Rosecler; CHIARA, Ivone Guerreiro di. Das redes sociais à inovação. Ciência da Informação, [s.1.], v. 34, n. 2, p. 93-104, ago. 2005. 